\title{
Karadeniz Teknik Üniversitesi Kanuni Kampüsü’nde Bazı Ofislerde Radon Gazı Ölçümü ve Çevrelerindeki Topraklarda Radyonüklid Seviyeleri
}

\author{
Selcen UZUN DURAN ${ }^{1 *}$, Belgin KÜÇÜKÖMEROĞLU² \\ ${ }^{1}$ Karadeniz Teknik Üniversitesi, Sağglk Hizmetleri MYO, Tıbbi Görüntüleme Bölümü, Trabzon \\ ${ }^{2}$ Karadeniz Teknik Üniversitesi, Fizik Bölümü, Trabzon \\ (ORCID: 0000-0003-4943-4654) (ORCID: 0000-0003-3963-3764)
}

\begin{abstract}
$\ddot{O} \mathbf{z}$
Bu çalışmada KTÜ Kanuni Kampüsü'nde ofislerde radon gazı seviyesi ölçülmüş ve çalışanlar için radondan kaynaklanan doz eşdeğerleri tahmin edilmiştir. Radon gazı ölçümleri 30 ofiste yapılmıştır. Ölçümler üçer katlı on binanın her bir katında yapılmış ve katlara göre radon gazı değerleri karșılaştırılmıştır. Çalışanlar zamanının çoğunu ofislerinde geçirdikleri için ofislerde radon gazı ölçümü önemlidir. Radon gazı ölçümleri ALPHAGUARD PQ 2000 radon monitörü ile ölçülmüş, sonuçlar uluslararası değerler ile karşılaş̧ırılmıştır. KTÜ Kanuni Kampüsünde ölçülen radon gazı değerleri izin verilen limit değerlerin altındadır. Ayrıca seçilen bu 10 binanın etrafindan alınan toprak örneklerinde radyonüklid analizi yapılmış ve değerler uluslararası kuruluşların izin verdiği limit seviyelerle karşılaştırılmıştır.
\end{abstract}

Anahtar kelimeler: Radon-222, Alpha-Guard, Eşdeğer Doz

\section{Radon Gas Measurement and Radionuclide Levels in Soil Surrounding in Some Offices of Karadeniz Technical University Kanuni Campus}

\begin{abstract}
In this study, radon concentration was measured in offices at the Kanuni Campus of Karadeniz Technical University to estimate the effective dose of radon for office workers. Radon gas measurements were made in thirty offices. Measurements were made on each floor of the three floors of ten building and the level of the radon was compared to the floors. The measurement of radon concentration levels is important in campus offices because of where office workers spend most of their time in offices. Radon measurements were performed by an ALPHAGUARD PQ 2000 radon gas analyser and the results obtained in this study were compared with the international recomended values. The radon levels obtained in most assesed offices in the Kanuni Campus of Karadeniz Technical University were found to be within the permissible reference levels. In addition, radionuclide analysis was performed in the soil samples taken around these 10 buildings and the values were compared with the limit levels allowed by international organizations.
\end{abstract}

Keywords: Radon-222, Alpha-Guard, Equivalent dose

\section{Giriş}

Sağlık sorunlarının oluşumunda iki temel neden vardır; bünyesel ve çevresel etmenler. Çevresel etmenler ve bunlara neden olan öğeler halk sağlığ açısından giderek daha önemli olmaktadır ve bu etmenlerin toplum sağlı̆̆ üzerindeki etkileri kontrol altında tutulmaya çalışılmaktadır. Çevrede insan sağlığını doğrudan veya dolaylı etkileyebilecek etkenlerin başında insanların var oldukları günden bu yana birlikte yaşamakta oldukları doğal ve yapay yollardan maruz kaldıkları radyasyon gelmektedir. Radyasyon sürekli iç içe olduğumuz, yaşadığımız çevrenin bir parçasıdır. Radyasyonun temel kaynakları, kayalar ve toprakta bulunan doğal radyonüklidlerden kaynaklanan radyasyon ile havadaki

\footnotetext{
* Sorumlu yazar: selcenduran@ktu.edu.tr

Geliş Tarihi: 11.06.2019, Kabul Tarihi: 24.09.2019
} 
ve yiyeceklerdeki doğal radyoaktif maddeler ve kozmik ışımalardır. Uranyumun doğal bir radyoizotopu olan ${ }^{238} \mathrm{U}$ değişik konsantrasyonlarda kaya ve topraklarda bulunur. ${ }^{238} \mathrm{U}$ ' nun doğal bozunma zincirinden radyoaktif olan ve soygaz özelliği gösteren ${ }^{222} \mathrm{Rn}$ oluşur. Radon, renksiz, kokusuz, tatsız ağır bir gazdır. 86 atom numarası ile periyodik cetvelin soygazlar sinıfinda yer alır. Radonun yarılanma ömrü 3,82 gündür ve $5,48 \mathrm{MeV}$ enerjili bir $\alpha$-parçacığg yayınlar. İnsanların maruz kaldığı radyasyonun $\% 85^{\prime} \mathrm{i}$ doğal kaynaklı olup, maruz kalınan doğal radyasyonun yarısının nedeni radon gazıdır [1].

Yer kabuğunda doğal süreçler sonucunda oluşan radonun çevreye yayılım göstermesi, coğrafik bölgenin jeolojik yapısıyla yakından ilişkilidir. Evlerdeki ve iş yerlerindeki radon gazının kaynakları, binaların temelindeki kaya, toprak ve yeraltı suları ve iklim koşullarıdır [2]. Oluşan radon ve diğer gazlar toprak boyunca yükselir ve binanın altında bir basınç oluşturur. Bu basınçtan dolayı radon gazı bina içine sızar. Dünya genelinde ülkelere göre değişiklik göstermekle birlikte kapalı mekanlar (evler, işyerleri, okullar, tüneller, metro istasyonları ve yeraltı maden ocakları) başta olmak üzere hemen her yerde değişik miktarda radon gazı bulunur [3]. İnsanlar zamanının önemli bir kısmını kapalı alanlarda geçirdiği için kapalı alanlarda radon ayrı bir önem kazanmaktadır.

Radyoaktif bozunmaya uğrayan radon gazı, solunum ve sindirim yoluyla vücuda alındığında, yaydığı alfa parçacıkları yolu ile akciğer ve mide dokularını radyasyona maruz bırakarak, dokulara hasar verebilirler. Yüksek dozda radyasyona maruz kalınması, akciğer kanserinin sigaradan sonra ikinci nedenidir [4]. Radon ve bozunma ürünlerine maruz kalan insanların, akciğer kanserine yakalanma olasılığının yüksek olduğu, ICRP-2010 raporunda belirtilmiştir [5].

Sağlık üzerine olumsuz etkileri nedeniyle, dünya genelinde, kapalı mekanlarda özellikle evlerde, iş yerlerinde, okullarda radon ölçümü çalışmaları yürütülmektedir. Bu çalışmaların yanında, metro istasyonları, kaplıcalar, madenler, fabrikalar, mağaralar, dükkanlar vb. iş yerlerini kapsayan çalışmalar da yapılmaktadır.

Ülkemizde ise, özellikle evlerde ve iş yerlerinde radon konsantrasyonu ölçüm çalışmaları yapılmıştır. Madenlerde [6-10], termal kaplıcalarda [11-14], mağaralarda [15-18] ve okullardaki (veya kamu binalarındaki) [19-20] çalışmaların sayısı gün geçtikçe artmaktadır.

Trabzon'da ise evlerde ve okullarda radon gazı seviyesi ölçümleri pasif radon dedektörü kullanılarak yapılmıştır [21-22]. Fakat Karadeniz Teknik Üniversitesi Kanuni Kampüsü’nde daha önce böyle bir çalışma yapılmamıştır.

Bu çalışmanın amacı Karadeniz Teknik Üniversitesi Kanuni Kampüsü’nde bazı ofislerde radon gazı ölçümü ile ofis çevresindeki topraklarda radyonüklid ölçümü yapıp, çalışanlar için radondan kaynaklanan yıllık etkin doz eşdeğerlerini hesaplamaktır.

\section{Materyal ve Metot}

\section{1. Çalıșma Alanı}

Çalışma Türkiye'nin Doğu Karadeniz Bölgesi'nde bulunan Trabzon ilindeki Karadeniz Teknik Üniversitesi Kanuni Kampüsü'nde gerçekleştirilmiştir (Şekil 1). 1955 yılında kurulan Karadeniz Teknik Üniversitesi, İstanbul ve Ankara illeri dışında Türkiye' de kurulan ilk üniversitelerden biridir. 1 milyon 53 bin 839 metrekarelik bir alanı kaplayan kampüste yaklaşık 60 bin öğrenciye hizmet verilmektedir [23]. Çalışmada Kanuni kampüsü eğitim alanında ve Doğu Karadeniz Bölgesi'nde birçok kişiye hizmet veren 800 yatak kapasiteli Farabi Hastanesinde gerçekleştirilmiştir. Eğitim alanı kampüsün kuzey bölümünde, $1000 \mathrm{~m}$ uzunluğundaki ana arter üzerinde bulunan eğitim birimleri, rektörlük, idari binalar, kütüphane, spor alanları, kongre binası, şenlik alanı, futbol sahası ve öğrenci yurtlarından oluşmaktadır [24]. 


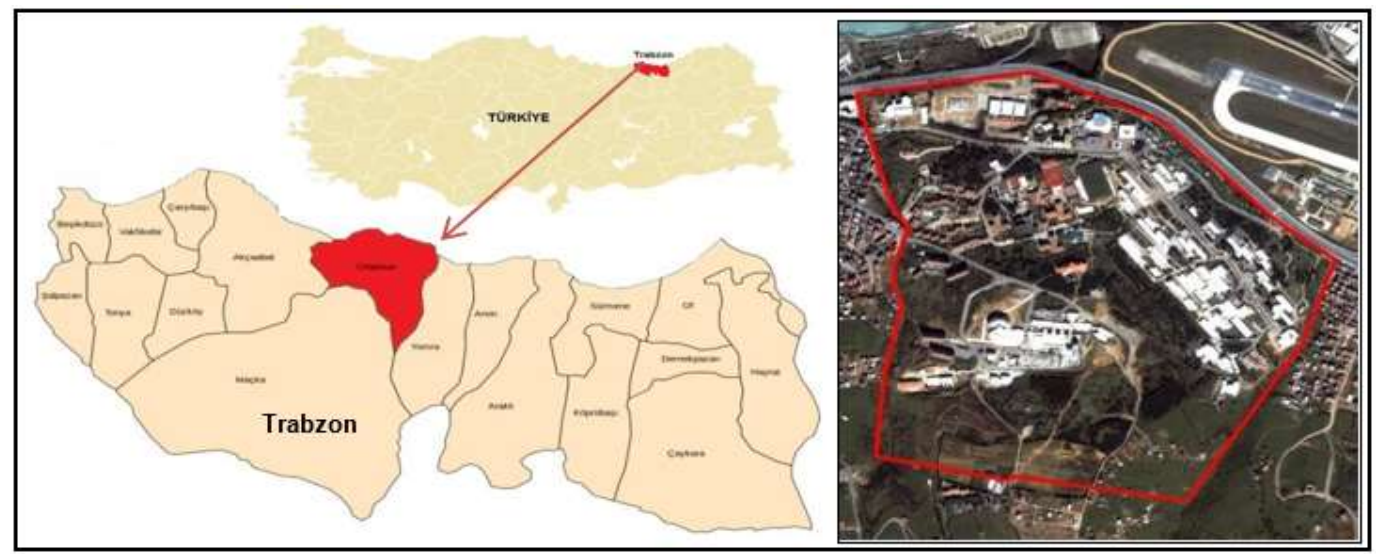

Şekil 1. Karadeniz Teknik Üniversitesi Kanuni Kampüsü [24].

\subsection{Yöntem}

2017-2018 y1llarında, Karadeniz Teknik Üniversitesi Kanuni Kampüsü'nde belirlenen 10 farklı binanın üç katında birer ofis olmak üzere, toplam 30 ofiste radon gazı ölçümleri yapılmıştır.

Radon, uranyum serisinin bozunma zincirinde bulunduğundan dolayı binanın altındaki toprağın uranyum miktarı, binalarda radon gazı seviyesinin değeri ile ilişkilidir. Radon gazının binaya girişinin temel nedeni, binanın temelinin altındaki toprak ile bina arasında oluşan sıcaklık ve basınç farkından dolayı oluşan gaz akışıdır. Bu gaz akışı binada bulunan çatlaklar ve boşluklardan bina içine sızmaktadır. Ayrıca binanın yapı malzemeleri de radon gazı üretmektedir. Kapalı ortamlarda radon gazı değerini etkileyen bir diğer etmen binanın havalandırma koşullarıdır. Bu çalışmada incelenen ofislerin tümü betonarme yapıda olmakla birlikte havalandırma koşulları ve binanın üzerinde bulunduğu toprağın yapısı farklı1ık gösterebilir. Bu nedenden dolayı radon gazı ölçümlerine ilave olarak binaların yakın çevresinden alınan toprak örneklerinde radyonüklid analizi yapılmıştır.

\subsubsection{Radon Gazı Ölçümü}

Bina içi radon seviyeleri iki farklı ölçüm tekniği kullanılarak yapılabilir. Bunlardan birisi aktif (anlık olarak ), diğeri pasif (belli bir zaman süresince) ölçüm tekniğidir [25]. Bu çalışmada aktif olarak ölçüm yapan Alpha GUARD PQ-2000 radon dedektörü kullanılmıştır.

Alpha GUARD PQ-2000 radon ölçüm cihazı yerinde ölçüm yapabilen taşınabilir bir cihazdır. Cihaza tümleşik olarak bulunan iyon odası (alfa spektroskobi pulse sayımı) sayesinde ortamın anlık radon değeri ölçülebilmektedir. Aynı zamanda cihaz radon değeri ile birlikte eş zamanlı olarak hava sıcaklığı, hava basıncı ve havanın nemi gibi diğer parametreleri de ölçmektedir. 2-2.000.000 Bq/ $\mathrm{m}^{3}$ aralığındaki radon yoğunlukları ölçebilen cihaz, bilgisayara bağlanarak veri depolanmakta ve veriler analiz edilebilmektedir. Bu çalışmada DataEXPERT yazılımı kullanılarak, alınan veriler analiz edilmiştir. AlphaGUARD aktif radon ölçüm cihazı ile her bir ofiste bir haftalık ölçümler yapılmıştır. Bu ölçümlerde 10 dk. Difüzyon modunda çalıştırılan cihaz Şekil 2'de görülmekledir.

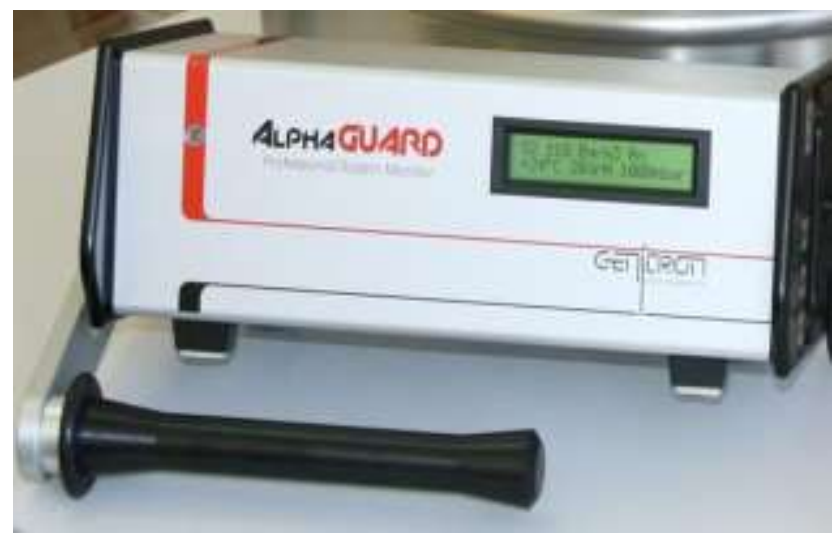

Şekil 2. AlphaGUARD aktif radon ölçüm cihazı. 
İç ortamdaki hava için radon gazından kaynaklanan yıllık etkin doz eşdeğeri UNSCEAR da belirtilen parametreler dikkate alınarak aşağıdaki formüle göre hesaplanmıştır [26].

$A E D E\left(\frac{m S v}{y}\right)=C R n . F . O . D C F$

Burada $C R n$ iç hava ortamındaki radon konsantrasyonunu, $F$ radon ve bozunum ürünlerinden kaynaklanan denge faktörünü $(0,4), O$ iç ortamda geçirilen süreyi (çalışanlar için yıllık ortalama 2000 saat) ve $D C F$ radondan kaynaklanan doz dönüşüm faktörünü $7,9 \times 10^{-6} \mathrm{mSv} \mathrm{h}^{-1}\left(\mathrm{~Bq} \mathrm{~m}^{-3}\right)^{-1}$ göstermektedir [26].

\subsubsection{Radyonüklid Analizi}

Çalışmada toprak numunelerinin radyoaktivite analizleri için, KTÜ Fen Fakültesi Fizik Bölümü Laboratuvarında bulunan çok kanallı gama spektroskopisi kullanılmıştır. Gamma spektroskopik ölçümler Canberra, yüksek saflıkta coaxial Ge dedektörü (GC 1519 model) kullanılarak yapılmıştır. Bu detektör \%15'lik relatif verime, $1332,5 \mathrm{keV}$ 'de $1,9 \mathrm{keV}$ rezülüsyona sahiptir. Elde edilen ölçümlerin analizi Genie-2000 programı kullanılarak yapılmıştır.

Toprak numuneleri yüzeyden $15-20 \mathrm{~cm}$ derinliğe inilerek toplanmıştır. Numuneler alınırken rastlanan bitki ve kök artıkları, çürümüş ağaç, yaprak ve dalları gibi biyolojik kalıntılar örnekten ayrılmıştır. Yalnız toprak almaya dikkat edilerek çakıl ve taşlar da numune dışına bırakılmıştır. Numuneler önceden etiketlenmiş temiz, ağızları kapanabilen naylon torbalara konulup laboratuvara getirilmiştir. Toplanan numuneler oda sıcaklığında kurutulmuş, öğütme ve eleme işlemleri yapılmıştır. Toprak örnekleri 80 Mesh'lik elekten geçirilerek homojen olması sağlanmıştır. Deney geometrisine uygun biçimde hazırlanan toprak örnekleri, deney geometrisine uygun kapların içine konulmuş ve ağızları sıkıca kapatılarak ${ }^{238} \mathrm{U}$ ve ${ }^{232} \mathrm{Th}$ ürünleri arasındaki radyoaktif dengenin oluşması için 1 ay süreyle bekletilmiştir. $\mathrm{Bu}$ işlemler sonucunda numuneler sayıma hazır hale getirilmiştir. Ölçüm sonucunda alınan spektrumlarda, ${ }^{238} \mathrm{U}$ bozunma ürünü ${ }^{214} \mathrm{~Pb}(295,2 \mathrm{keV}),{ }^{214} \mathrm{~Pb}(352 \mathrm{keV}),{ }^{214} \mathrm{Bi}(609,4$ $\mathrm{keV}) ;{ }^{232} \mathrm{Th}$ bozunma ürünü ${ }^{212} \mathrm{~Pb}(238,6 \mathrm{keV}),{ }^{208} \mathrm{Tl}(583,1),{ }^{228} \mathrm{Ac}(911,1 \mathrm{keV})$ ve ${ }^{40} \mathrm{~K}(1460 \mathrm{keV})$ pikleri belirlenmiş ve aşağıda verilen bağıntı kullanılarak aktivite değerleri hesaplanmıştır.

$A=N /(m x \varepsilon x P x t)$

Bağıntıda $\mathrm{A}$ aktivite değeri, $\mathrm{N}$ net sayım alanı (toplam alan-background alanı), m numunenin net kütlesi, $\mathcal{E}$ verim, p(bolluk) olasılık, t sayım zamanıdır. Aktiviteler hesaplandıktan sonra ise soğurulan doz ve yıllık etkin doz eşdeğeri hesaplanmıştır. Soğurulan doz;

$D\left(\frac{n G y}{s}\right)=\left(0,462 x U^{238}\right)+\left(0,604 x T h^{232}\right)+\left(0,0417 x K^{40}\right)$

bağıntısı ile hesaplandıktan sonra Yıllık Etkin Doz Eşdeğeri aşağıda ki bağıntıdan hesaplanmıştır.

$\operatorname{AEDE}\left(\frac{\mu S v}{y}\right)=$ Soğurulan Gama DozuxÇevresel Gama Dozu Dönüşüm FaktörüxMeşguliyet FaktörüxZaman

Bu eşitlikte; Çevresel Gama Dozu Dönüşüm Faktörü, hem kapalı ortam içinde hem de kapalı ortam dışında yapılan ölçümlerde değişmemekte ve $0,7 \mathrm{~Sv} /$ Gy olarak alınmaktadır. Meşguliyet Faktörü ise insanların bu ışınlara maruz kaldıkları süredir. Bu çalışmada, Denklem 4'de meşguliyet faktörü, insanların zamanlarının \%20'sini açık alanlarda ve \%80'ini kapalı alanlarda geçirdikleri göz önüne alınarak, kapalı ortam için 0,8 ve kapalı ortam dışı için ise 0,2 olarak alınmıştır. Zaman ise, bir yıldaki saat sayısıdır (8760 s/y) [1].

\section{Bulgular ve Tartışma}

Karadeniz Teknik Üniversitesi Kanuni Kampüsü’nde toplam 30 ofiste her bir ofiste 1 hafta süreli ölçülen aktif radon gazı dedektörü verileri analiz edilerek ve Denklem 1 kullanılarak yıllık etkin doz eşdeğerleri 
hesaplanmıştır. Ofis ortamında radon konsantrasyonu ve çalışan personelin aldığ1 y1llık etkin doz eşdeğeri Tablo 1'de verilmektedir.

Tablo 1. Ofis ortamında radon gazı konsantrasyonu ve çalışan personelin aldığ 1 yıllık etkin doz eşdeğeri

\begin{tabular}{|c|c|c|c|}
\hline Ofis & Kat & Ortalama Radon Konsantrasyonu (Bq/m³) & AEDE(mSv/y) \\
\hline \multirow[t]{3}{*}{ O-1 } & O1K1 & $79 \pm 26$ & 0,50 \\
\hline & $\mathrm{O} 1 \mathrm{~K} 2$ & $67 \pm 22$ & 0,42 \\
\hline & $\mathrm{O} 1 \mathrm{~K} 3$ & $54 \pm 9,5$ & 0,34 \\
\hline \multirow[t]{3}{*}{$\mathrm{O}-2$} & $\mathrm{O} 2 \mathrm{~K} 1$ & $90 \pm 16$ & 0,57 \\
\hline & $\mathrm{O} 2 \mathrm{~K} 2$ & $46 \pm 15$ & 0,29 \\
\hline & $\mathrm{O} 2 \mathrm{~K} 3$ & $20 \pm 8$ & 0,12 \\
\hline \multirow[t]{3}{*}{$\mathrm{O}-3$} & O3K1 & $90 \pm 29$ & 0,57 \\
\hline & $\mathrm{O} 3 \mathrm{~K} 2$ & $78 \pm 11$ & 0,49 \\
\hline & $\mathrm{O} 3 \mathrm{~K} 3$ & $53 \pm 17$ & 0,33 \\
\hline \multirow[t]{3}{*}{$\mathrm{O}-4$} & O4K1 & $26 \pm 6$ & 0,16 \\
\hline & $\mathrm{O} 4 \mathrm{~K} 2$ & $17 \pm 6$ & 0,10 \\
\hline & $\mathrm{O} 4 \mathrm{~K} 3$ & $13 \pm 6$ & 0,08 \\
\hline \multirow[t]{3}{*}{ O-5 } & O5K1 & $53 \pm 6$ & 0,33 \\
\hline & O5K2 & $46 \pm 6$ & 0,3 \\
\hline & $\mathrm{O} 5 \mathrm{~K} 3$ & $32 \pm 6$ & 0,2 \\
\hline \multirow[t]{3}{*}{ O-6 } & O6K1 & $234 \pm 27$ & 1,5 \\
\hline & O6K2 & $208 \pm 58$ & 1,3 \\
\hline & O6K3 & $113 \pm 32$ & 0,7 \\
\hline \multirow{3}{*}{ O-7 } & O7K1 & $78 \pm 12$ & 0,23 \\
\hline & O7K2 & $65 \pm 13$ & 0,41 \\
\hline & O7K3 & $37 \pm 7$ & 0,5 \\
\hline \multirow[t]{3}{*}{$\mathrm{O}-8$} & O8K1 & $54 \pm 14$ & 0,12 \\
\hline & O8K2 & $43 \pm 9$ & 0,27 \\
\hline & O8K3 & $19 \pm 7,5$ & 0,34 \\
\hline \multirow[t]{3}{*}{ O-9 } & O9K1 & $49 \pm 9$ & 0,31 \\
\hline & O9K2 & $38 \pm 10$ & 0,24 \\
\hline & O9K3 & $25 \pm 12$ & 0,16 \\
\hline \multirow[t]{3}{*}{ O-10 } & O10K1 & $64 \pm 10$ & 0,40 \\
\hline & O10K2 & $36 \pm 9$ & 0,25 \\
\hline & O10K3 & $12 \pm 3$ & 0,08 \\
\hline
\end{tabular}

Tablo 1 incelendiğinde, Ofis 6'nın 1. Katında (O6K1) en yüksek radon gazı değeri (234 \pm 27$)$ olduğu görülmektedir. En düşük radon gazı değerinin (12 \pm 3$)$ ise 10. Ofisin 3. Katında olduğu görülmektedir. Ortalama radon konsantrasyonu en düșük $\left(18,6 \mathrm{~Bq} / \mathrm{m}^{3}\right)$ olan ofis 4. ofis, ortalama radon konsantrasyonu en yüksek olan $\left(185 \mathrm{~Bq} / \mathrm{m}^{3}\right)$ ofis 6 . Ofistir. Karadeniz Teknik Üniversitesi Kanuni Kampüsü'nde yapılan ölçümlerde 30 ofisin ortalama radon gazı seviyesi $61 \mathrm{~Bq} / \mathrm{m}^{3}$ olarak belirlenmiştir.

Ofis-6'nın 3. Katında yapılan ölçümün ekran görüntüsü olan Şekil 3'de havalandırmanın, kapalı ortamdaki radon gazı konsantrasyonuna etkisini açıkça görülmektedir. Grafikte radon gazı değerlerinin artıp, azaldığı görülmektedir. Radon gazı değerleri camların açılıp havalandırma sağlandığı durumlarda azalmakta, camlar kapatıldığında artmaktadır. Bu ölçümde camlar gece kapanıp sabah açılmıştır. Camlar kapandığında ortamdaki radon gazı seviyesi yavaş yavaş artmakta, camlar açıldığında ise azalmaktadır. Ölçümün yapıldığı AlphaGUARD-2000 cihazı, anlık radon gazı seviyesi ile birlikte eş zamanlı olarak basınç, sıcaklık ve nem değerlerini vermektedir. Grafikte bu değerler görülmektedir. 


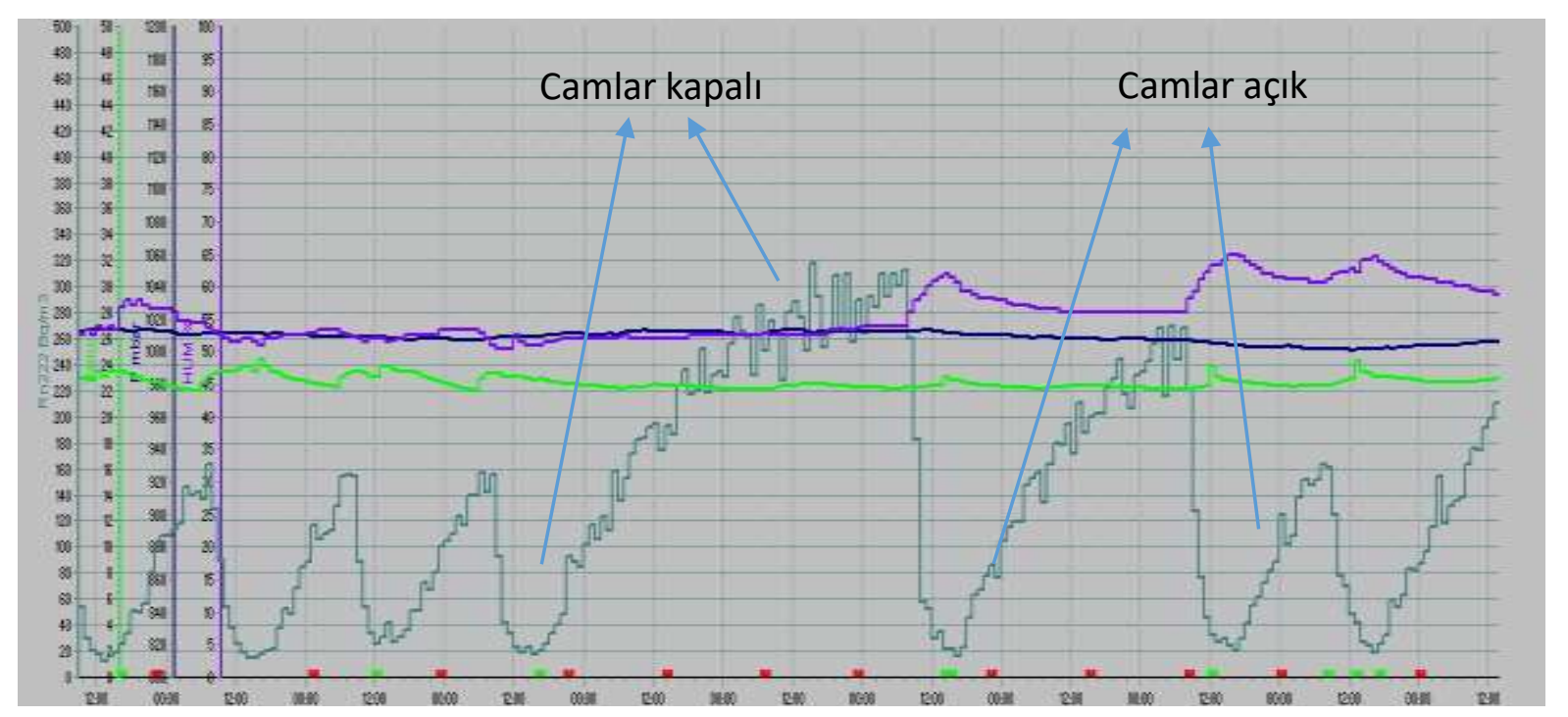

Şekil 3. Havalandırma ile ortamdaki radon gazı değişimi (Ofis-6'nın 3. Katında yapılan ölçümün ekran görüntüsü)

Gama spektroskopik analizi için seçilen 10 binanın çevresinden alınan toplam 14 toprak numunesinin ${ }^{238} \mathrm{U},{ }^{232} \mathrm{Th},{ }^{40} \mathrm{~K}$ doğal radyoaktif elementinin aktiviteleri hesaplanmış ve Tablo 2'de verilmiştir. 14 adet toprak numunesinin ortalama ${ }^{238} \mathrm{U}$ aktivitesi $59 \pm 1 \mathrm{~Bq} / \mathrm{kg}$ olarak hesaplanmıştır. En düşük aktivite değeri $35 \pm 6 \mathrm{~Bq} / \mathrm{kg}$, en yüksek aktivite değeri ise $81 \pm 8 \mathrm{~Bq} / \mathrm{kg}$ dır. Ortalama ${ }^{232} \mathrm{Th}$ aktivitesi $26 \pm 2 \mathrm{~Bq} / \mathrm{kg}$ olup, değerler $12 \pm 2 \mathrm{~Bq} / \mathrm{kg}-44 \pm 6,5 \mathrm{~Bq} / \mathrm{kg}$ aralığındadır. Ortalama ${ }^{40} \mathrm{~K}$ aktivitesi $603 \pm 8$ $\mathrm{Bq} / \mathrm{kg}$ olarak hesaplanmıştır.

Tablo 2. Binaların etrafindan toplanan toprak örneklerinin gama spektroskopik analizleri

\begin{tabular}{lccccc}
\hline Numune ad1 & $\begin{array}{c}{ }^{238} \mathrm{U} \\
(\mathrm{Bq} / \mathrm{kg})\end{array}$ & $\begin{array}{c}{ }^{232} \mathrm{Th} \\
(\mathrm{Bq} / \mathrm{kg})\end{array}$ & $\begin{array}{c}{ }^{40} \mathrm{~K} \\
(\mathrm{~Bq} / \mathrm{kg})\end{array}$ & $\begin{array}{c}\mathrm{D} \\
(\mathrm{nGy} / \mathrm{s})\end{array}$ & $\begin{array}{c}\text { AEDE } \\
(\mu \mathrm{Sv} / \mathrm{y})\end{array}$ \\
\hline $\mathrm{T} 1$ & $47 \pm 6$ & $18 \pm 4$ & $540 \pm 39$ & 58 & 71 \\
$\mathrm{~T} 2$ & $35 \pm 6$ & $12 \pm 2$ & $628 \pm 51$ & 50 & 61 \\
$\mathrm{~T} 3$ & $65 \pm 8$ & $16 \pm 7$ & $501 \pm 56$ & 61 & 75 \\
$\mathrm{~T} 4$ & $56 \pm 7$ & $19 \pm 5$ & $627 \pm 51$ & 37 & 45 \\
$\mathrm{~T} 5$ & $59 \pm 6$ & $21 \pm 7$ & $550 \pm 44$ & 63 & 77 \\
$\mathrm{~T} 6$ & $67 \pm 7$ & $19 \pm 6$ & $516 \pm 31$ & 64 & 78 \\
$\mathrm{~T} 7$ & $40 \pm 5$ & $17 \pm 5$ & $594 \pm 42$ & 53 & 54 \\
$\mathrm{~T} 8$ & $47 \pm 4$ & $21 \pm 4$ & $562 \pm 36$ & 58 & 71 \\
$\mathrm{~T} 9$ & $61 \pm 7$ & $44 \pm 6,5$ & $718 \pm 58$ & 85 & 104 \\
T10 & $58 \pm 9$ & $22 \pm 7$ & $687 \pm 62$ & 72 & 88 \\
T11 & $81 \pm 8$ & $41 \pm 7$ & $710 \pm 55$ & 92 & 113 \\
T12 & $77 \pm 7$ & $33 \pm 7$ & $609 \pm 55$ & 81 & 99 \\
T13 & $66 \pm 7$ & $40 \pm 6$ & $601 \pm 50$ & 80 & 98 \\
T14 & $73 \pm 7$ & $37 \pm 7$ & $592 \pm 50$ & 80 & 98 \\
Ortalama & $59 \pm 1$ & $26 \pm 2$ & $603 \pm 8$ & 66 & 81 \\
\hline Dünya & 35 & 30 & 400 & UNSCEAR $(2000)$ \\
ortalamas1 & & & & & \\
\hline & & & & &
\end{tabular}




\section{Sonuç ve Öneriler}

İnsanlar kapalı alanlarda bulunan radon gazından dolayı çeşitli sağlık riskleri ile karşılaşmaktadırlar. Ayrıca ülkemizde de akciğer kanseri yaygın kanser türlerindendir. Bu nedenle kapalı ortamlarda radon gazı değerlerinin tespit edilmesi önemlidir. Karadeniz Teknik Üniversitesi Kanuni Kampüsü’nde toplam 30 ofiste yapılan radon gazı ölçümlerinde, ortalama radon seviyesinin $61 \mathrm{~Bq} / \mathrm{m}^{3}$ olduğu tespit edilmiştir. Çalışmada radon gazı değerlerinin bina katlarına göre değişimi de incelenmiştir. Radon gazının katlara göre değişimi Şekil 4'de görülmektedir. Ortalama radon konsantrasyonu birinci katta $82 \pm 9 \mathrm{~Bq} / \mathrm{m}^{3}$, ikinci katta $64 \pm 6 \mathrm{~Bq} / \mathrm{m}^{3}$, üçüncü katta $38 \pm 5 \mathrm{~Bq} / \mathrm{m}^{3}$ değerindedir. Birinci kattan yukarıya doğru çıkıldıkça radon gazı seviyesi azalmaktadır. Toprağa dolayısı ile bina zeminine daha yakın olan bodrum, giriş ve birinci kattaki ofislerde radon gazı seviyesinin ikinci ve üçüncü katlara göre daha yüksek olması beklenen bir sonuçtur. Çünkü radon gazı toprakta bulunan ${ }^{238} \mathrm{U}^{\prime}$ un bozunması sonucu oluşmaktadır.

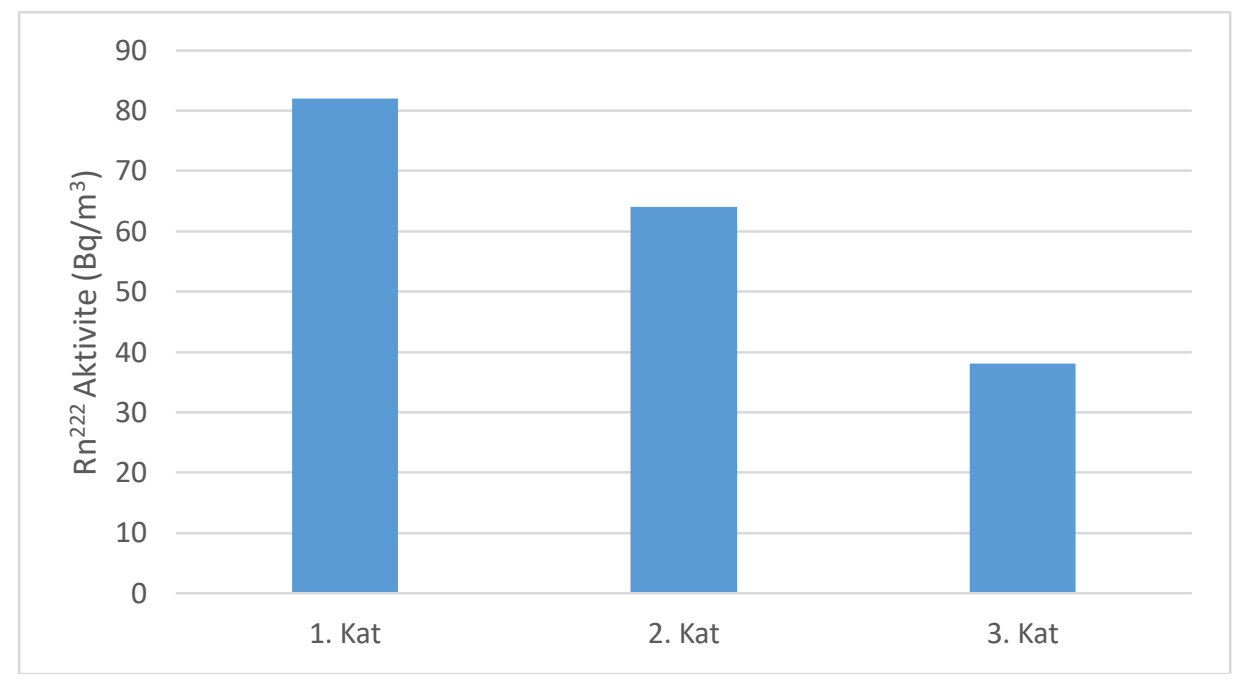

Şekil 4. Ortalama radon konsantrasyonunun katlara bağlı değişimi

Ev ve iş yerlerinde radon gazı değerleri için ulusal ve uluslararası kuruluşlarca limit değerler belirlenmiştir. Bu değerler Tablo 3'de verilmiştir. Bu değerlerin aşılması durumunda, ortamdaki radon konsantrasyonunu düşürme amaçlı tedbirlerin alınması tavsiye edilmektedir.

Tablo 3. Ev ve iş yerlerinde radon gazı değerleri için ulusal ve uluslararası kuruluşlarca belirlenen limitler [27].

\begin{tabular}{lcc}
\hline \multirow{2}{*}{ Organizasyon } & \multicolumn{2}{c}{ Tavsiye edilen limitler $\left(\mathrm{Bq} / \mathrm{m}^{3}\right)$} \\
& Ev & İş yeri \\
\hline ICRP & $\leq 300$ & $\leq 1000$ \\
WHO & $\leq 100$ & \\
AB & $\leq 300$ & $\leq 1000$ \\
TAEK & $\leq 400$ & $\leq 1000$ \\
\hline
\end{tabular}

Karadeniz Teknik Üniversitesi Kanuni Kampüsü'nde belirlenen 10 binada toplam 30 ofiste yapılan radon gazı ölçüm sonuçları incelenip limit değerler ile karşılaştırıldığında, Tablo 1'deki sonuçların ulusal ve uluslararası kuruluşlarca belirlenen limit seviyelerden düşük olduğu görülmektedir. En yüksek değer olan $234 \pm 27 \mathrm{~Bq} / \mathrm{m}^{3}$ değerinin, ICRP ve TAEK'in iş yeri için belirlediği limit değerlerinin çok altında olduğu görülmektedir. 
Tablo 4. İç havadaki ${ }^{222} \mathrm{Rn}$ seviyelerinin ve bu çalışmada belirlenen yıllık etkili dozların literatürdeki çalışmalarla karşılaştırılması.

\begin{tabular}{lllll}
\hline Kurum & $\begin{array}{c}{ }^{222} \mathrm{Rn} \\
\left(\mathrm{Bq} / \mathrm{m}^{3}\right)\end{array}$ & $\begin{array}{l}\text { AEDE } \\
(\mathrm{mSv} / \mathrm{y})\end{array}$ & Ülke & Referans \\
\hline Okul & $15-1390$ & - & İtalya & 28 \\
Okul & $301-1582$ & - & İspanya & 29 \\
Okul & $31-157$ & $0.06-1.40$ & Trabzon, Türkiye & 21 \\
Okul & $10-96.5$ & $0.36-0.38$ & Sakarya, Türkiye & 30 \\
Kampüs & $27-213$ & $0.16-2.32$ & Pakistan & 31 \\
Kampüs & $157-495$ & $0.99-3.12$ & Nijerya & 32 \\
Kampüs & $40-335$ & $0.79-4.27$ & İzmir, Türkiye & 33 \\
Kampüs & $0.2-94$ & $0.18-2.00$ & Sakarya, Türkiye & 34 \\
Kampüs & $12-234$ & $0.08-1.5$ & Trabzon, Türkiye & Bu çalı̧̧ma \\
\hline
\end{tabular}

Tablo 4'de radon gazı değeri ve yıllık etkin doz eşdeğerleri literatürdeki benzer çalışmalarla karşılaştırılmıştır. Sonuçlar incelendiğinde Karadeniz Teknik Üniversitesi Kanuni Kampüsü’nde ofislerde radon gazı seviyelerinin, Trabzon'da daha önce okullar için yapılan çalışmanın sonuçları ile benzer olduğu görülmektedir.

Toprak örneklerindeki doğal radyoaktivite konsantrasyonları HPGe gama spektrometresi kullanılarak ölçülmüştür. Tablo 2' de bu çalışmadaki ${ }^{238} \mathrm{U},{ }^{232} \mathrm{Th},{ }^{40} \mathrm{~K}$ sonuçları verilmiştir. Topraklarda doğal radyonüklid seviyelerinin dünya ortalamas ${ }^{238} \mathrm{U},{ }^{232} \mathrm{Th}$, ve ${ }^{40} \mathrm{~K}$ için sirası ile $35 \mathrm{~Bq} / \mathrm{kg}, 30 \mathrm{~Bq} / \mathrm{kg}$, 400 Bq/kg dır. Karadeniz Teknik Üniversitesi Kanuni Kampüsü’nde radon ölçümü yapılan binaların çevresinden alınan toprak örneklerinde ${ }^{238} \mathrm{U},{ }^{232} \mathrm{Th},{ }^{40} \mathrm{~K}$ 'un ortalama aktivite konsantrasyonları sirasiyla $59 \pm 1 \mathrm{~Bq} / \mathrm{kg}, 26 \pm 2 \mathrm{~Bq} / \mathrm{kg}, 603 \pm 8 \mathrm{~Bq} / \mathrm{kg}$ olarak bulunmuştur. Topraktaki ${ }^{238} \mathrm{U}$ seviyesi dünya ortalamasının 1,7 katı, potasyum ise dünya ortalamasının 1,5 katı kadardır.

\section{Tartışma}

KTÜ Kanuni Kampüsü’nde ofislerde ölçülen radon gazı seviyesi $12 \mathrm{~Bq} / \mathrm{m}^{3}$ ile $234 \mathrm{~Bq} / \mathrm{m}^{3}$ değerleri arasında değişmektedir. Ortalama değer $61 \mathrm{~Bq} / \mathrm{m}^{3}$ dür. Bu değerler ICRP, TAEK, AB'nin iş yeri için önerdiği sınır değerlerinden $\left(1000 \mathrm{~Bq} / \mathrm{m}^{3}\right)$ oldukça düşüktür. Diğer taraftan, ICRP (ICRP, 1993) yıllık etkin doz için müdahale sınırını 3-10 mSv/y belirlemiştir. Bu çalışmada, radondan kaynaklanan yıllık etkin doz eşdeğerleri 0.08-1.5 mSv/y aralığındadır. Ortalaması ise $0.4 \mathrm{mSv} / \mathrm{y}$ dır. Bu doz değerleri ICRP değerinin altında olduğu sonucuna ulaş11ır.

Özellikle radon değerlerinin çalışma bölgesinde çalışma boyunca değişkenlik göstermesi sürekli radon ölçümlerinin gerekliliğini ortaya koymaktadır. Ortamdaki radon gazının havalandırma ile ortamdan uzaklaştığı bilinmektedir. Bu çalışmada radon gazı havalandırma ilişkisi bir kez daha ortaya konulmuştur. Çalışma ortamlarının sık sık havalandırılması ortamda biriken radon gazı seviyesinin düşmesi bakımından önemlidir.

\section{Yazarların Katkısı}

Çalışmada Belgin KÜÇÜKÖMEROĞLU fikir, kavram, tasarım, eleştirel inceleme, kaynak ve cihaz sağlama konusunda; Selcen UZUN DURAN ise veri toplama, analiz ve yorum, kaynak taramas1 ve makalenin yazımı konusunda katkı sağlamıştır.

\section{Çıkar Çatışması Beyanı}

Yazarlar arasında herhangi bir çıkar çatışması bulunmamaktadır.

\section{Araştırma ve Yayın Etiği Beyanı}

Yapılan çalışmada, araştırma ve yayın etiğine uyulmuştur. 


\section{Kaynaklar}

[1] UNSCEAR 2000. Sources and effects of ionizing radiation, Report to General Assembly, with scientific Annexes United Nations, New York.

[2] Rahman S.U., Rafique M., Matiullah A.J. 2009. Radon measurement studies in workplace buildings of the Rawalpindi region and Islamabad capital area, Pakistan. Building and Environment, 45 (2): 421-426.

[3] TAEK, 2012. Teknik Rapor: Kapalı ortamlarda radon gazı.

[4] International Commission on Radiological Protection (ICRP), 2010. Lung cancer risk from radon and progeny and statement on radon, Publication report 115.

[5] International Atomic Energy Agency (IAEA), 2004. Radiation, people and the environment, Austria, https://www.iaea.org/sites/default/files/radiation0204.pdf (Erişim Tarihi: 12.02.2015).

[6] Fişne A., Ökten G., Çelebi N. 2004. Türkiye Taşkömürü Kurumu (TTK) yeraltı maden ocaklarında radon gazı yayılımının incelenmesi. Türkiye 14. Kömür Kongresi, Zonguldak, Türkiye, Bildiri Kitab1, s 193-202.

[7] Baldık R., Aytekin H., Çelebi N., Ataksor B., Taşdelen M. 2006. Radon concentration measurements in the Amasra coal mine, Turkey. Radiation Protection Dosimetry, 118 (1): 122125.

[8] Baldık R., Aytekin H., Çelebi N. 2009. Radon fluctuations in the Armutçuk coal mine, Turkey. Fresenius Environmental Bulletin, 18 (1): 87-91.

[9] Yılmaz A., Kürkçüoğlu M.E., Haner B. 2009. Nükleer iz dedektörlerinin konumlarının radon konsantrasyonu ölçümleri üzerine etkisi. X. Ulusal Nükleer Bilimler ve Teknolojileri Kongresi, Muğla, Türkiye, Bildiri Kitabı, s 256-262.

[10] Uzbey S., Tel E., Aytekin H., Albayrak N. 2013. Çorum ili yeraltı kömür ocaklarında radon yoğunluğu ölçümü. Karaelmas Fen ve Mühendislik Dergisi, 3 (1): 1-5.

[11] Durak S. 2010. Kütahya İli Kaplıca Sularında Radon-Radyum Konsantrasyonlarının Ve Kaplıcalardaki Kapalı Ortam Radon Konsantrasyonun Belirlenmesi. Yüksek Lisans Tezi, Dumlupınar Üniversitesi, Fen Bilimleri Enstitüsü, Kütahya, 85s.

[12] Kılıç N. 2011. Kükürtlü Kaplıcaları Atatürk Rehabilitasyon Merkezi’ndeki radon konsantrasyonunun belirlenmesi. Yüksek Lisans Tezi, Uludağ Üniversitesi, Fen Bilimleri Enstitüsü, Bursa, 94s.

[13] Akkuş İ. 2014. Afyonkarahisar Merkezdeki Kaplıcalarda Radon Konsantrasyonu ve Y1llık Etkin Doz Oranlarının Belirlenmesi. Yüksek Lisans Tezi, Afyon Kocatepe Üniversitesi, Fen Bilimleri Enstitüsü, Afyon, 83s.

[14] Duran S.U., Kucukomeroglu B., Damla N., Taskin H., Celik N., Cevik U., Ersoy H. 2017. Radioactivity Measurements and Risk Assessments of Spa Waters in Some Areas in Turkey. Isotopes in Environmental and Health Studies, 53 (1): 91-10.

[15] Aytekin H., Baldık R., Çelebi N., Ataksor B., Taşdelen M., Kopuz G. 2006. Radon measurements in the caves of Zonguldak (Turkey). Radiation Protection Dosimetry, 118 (1): 117-121.

[16] Haner B., Yılmaz A., Kürkçüoğlu M.E., Karadem A. 2010. Mencilis (Bulak) mağarasında radon seviyesi ölçümleri. Süleyman Demirel Üniversitesi Fen Bilimleri Enstitüsü Dergisi, 14 (3): 218 224.

[17] Karadem A. 2011. CR-39 Dedektörleri İle Mağaralarda Radon Konsantrasyonu Ölçümleri. Yüksek Lisans Tezi, Süleyman Demirel Üniversitesi, Fen Bilimleri Enstitüsü, Isparta, 97s.

[18] Çevik U., Kara A., Çelik N., Karabidak M., Çelik A. 2011. Radon Survey And Exposure Assessment İn Karaca And Çal Caves, Turkey. Water Air \& Soil Pollution, 214: 461-469.

[19] Karakılıç V., Bayraktar G., Kürkçüoğlu M.E., Haner B., Yılmaz A. 2009. S.D.Ü. Bilgi Merkezi'nde radon ölçümleri. Süleyman Demirel Üniversitesi Fen Bilimleri Enstitüsü Dergisi, 13 (3): 201-207.

[20] Kürkçüoğlu M.E., Bayraktar G. 2012. Süleyman Demirel Üniversitesi'nde bina içi radon konsantrasyonlarının nükleer iz dedektörleri kullanılarak belirlenmesi. Süleyman Demirel Üniversitesi Fen Bilimleri Enstitüsü Dergisi, 16 (2): 167-183.

[21] Çevik U., Çelik A., Çelik N., Özkalaycı F., Akbulut S. 2011. Assessment of Radiological Levels at Schools in Trabzon, Turkey. Indoor and Built Environment, 22 (2): 376-383. 
[22] Kurnaz A., Küçükömeroğlu B., Çevik U., Çelebi, N. 2011. Radon Level and Indoor Gamma Doses in Dwellings of Trabzon, Turkey. Applied Radiation And Isotopes, 69 (10): 1554-1559.

[23] KYSMP, 2016. Karadeniz Teknik Üniversitesi Kanuni Yerleşkesi Stratejik Master Planı. KTÜ Basımevi, Trabzon.

[24] Güneroğlu N., Bekar M., Aktürk E., Dihkan A. 2018. Hobby Gardens in Urban Green Area Systems; The Case Study of Karadeniz Technical University Kanunı Campus. Journal of Social And Humanities Sciences Research (JSHSR), 5: 2253-2263.

[25] Papastefanou C. 2002. An overview of instrumentation for measuring radon in soil gas and groundwaters. Journal of Environmental Radioactivity, 63: 271-283.

[26] Nikolov J., Todorovic N., Panti T., Forkapic S., Mrdja D., Bikit I., Krma M., Veskovic M. 2012. Exposure to Radon in the Radon Spa Niška Banja, Serbia. Radiation Measurements, 47 (6): 443 450.

[27] Kürkçüoğlu M.E., Tozun F. 2015. Isparta İl Merkezindeki İş Yerlerinde Atmosferik Radon Ölçümleri. SDU Journal of Science (E-Journal), 10 (1): 62-74.

[28] Venoso G., De Cicco F., Flores B., Gialanella L., Puglies M., Roca V., Sabbarese C. 2009. Radon concentrations in schools of the Neapolitan area. Radiation measurements, 44 (1): 127-130.

[29] Llerena J.J., Cortin D., Durán I., Sorribas R. 2010. ${ }^{222}$ Rn concentration in public secondary schools in Galicia (Spain). Journal of environmental radioactivity, 101 (11): 931-936.

[30] Kapda E., Altinsoy N. 2012. A Comparative Study of Indoor Radon Concentrations Between Dwellings And Schools. Radiation Physics and Chemistry, 81 (4): 383-386.

[31] Khan S.A., Ali S., Tufail M., Qureshi A.A. 2005. Radon Concentration Levels in Fatima Jinnah Women University Pakistan. Radioprotection, 40 (1): 11-27.

[32] Obed R.I., Ademola A.K., Vascotto M., Giannini G. 2011. Radon Measurements by Nuclear Track Detectors in Secondary Schools in Oke-Ogun Region, Nigeria. Journal of Environmental Radioactivity, 102 (11): 1012-1017.

[33] Alkan T., Karadeniz Ö. 2014. Indoor ${ }^{222}$ Rn Levels And Effective Dose Estimation of Academic Staff in Izmir-Turkey. Biomedical and Environmental Sciences, 27 (4): 259-267.

[34] Zenginerler Z., Ertugral F., Yakut H., Tabar E., Demirci N., Gunermelikoglu K. 2016. Measurement of Seasonal indoor Radon Concentration in Sakarya University, Turkey. Acta Physica Polonica A, 130 (1): 450-452. 